\title{
Demographic and attitudinal antecedents of consumers' use and self- investment trajectories over time in an online TV content platform
}

\author{
SAM VAN DER LINDEN \\ STEF NIMMEGEERS \\ KRISTOF GESKENS \\ BERT WEIJTERS
}

Sam Van der Linden (savdrlin.VanderLinden@UGent.be) is Ph.D. student at Ghent University, Department of Work, Organisation and Society; Dunantlaan 2, B-9000 Ghent, Belgium.

Stef Nimmegeers is Co-founder of digital product studio Bothrs, Vlasgaardstraat 52, 9000 Ghent, Belgium.

Kristof Geskens is Research Fellow at Vlerick Business School (kristof.geskens@ vlerick.be), Reep 1, B-9000 Ghent, Belgium.

Bert Weijters (bert.weijters@ugent.be) is associate professor of market research at Ghent University, Department of Work, Organisation and Society; Dunantlaan 2, B-9000 Ghent, Belgium. 


\title{
Demographic and attitudinal antecedents of consumers' use and self-
}

\author{
investment trajectories over time in an online TV content platform
}

\begin{abstract}
Purpose - To investigate if online TV content platforms create value for consumers (and increase use) by offering its users the possibility to self-invest in the service (by giving personal content preferences). We link demographic and attitudinal antecedents to the relation between self-investment and use.

Design/methodology/approach - Data was collected together with a Belgian media company $(N=4136)$. To test the effects a latent growth model was composed in a multigroup setting with gender as the grouping variable. The model is analyzed through structural equation modeling in Mplus 8.0.
\end{abstract}

Findings - In general, strong relations between self-investment and increased use were found, although the effect of self-investment on use was stronger for female consumers. Furthermore, we established strong hedonic effects on using and investing in the service. For men, easy to use platforms lead to less self-investment.

Research limitations/implications - Our findings are restricted to free services. Furthermore, attitudinal variables are antecedents of behaviors. However, a more complex interplay between behavioral and attitudinal variables is possible. Further research could use repeatedly measured attitudinal measures and link these to behaviors over time.

Practical implications - Service developers could offer different platform interactions to different segments to create consumer value. Women seem more receptive for extra functionalities, such as the possibility to indicate preferences. Men mainly focus on the content offered.

Originality/value - This study focuses on a new form of media distribution, online TV content platforms, where we investigate two related behaviors of users over time (selfinvestment and use) instead of a general approximation of use. Multi-source data was used. 
Over the last decade, television broadcasters have come under increasing competitive pressure from online content providers like Netflix (Matrix, 2014; Tryon, 2015). In response, many TV broadcasters have decided to not only broadcast their content in the traditional manner, but to additionally provide online access to the same content on demand, either as a paying service or financed through advertising (Mikos, 2016). For consumers this means that, rather than having to plan watching or recording their favorite program when it is being broadcasted, they have access to it whenever they like (Iyer \& Scherf, 2006).

To enable consumers to manage the content they want to watch, online TV content platforms typically offer a favorites functionality. That is, consumers can make a selection of programs they like, and this list is available on a specific page of the online platform (often the landing page). From an object design perspective, this simple action can be important to convince users to continue using the digital service. Through allowing the creation of a personal list, users can invest their own identity in and express it through the platform (Baxter, Aurisicchio, \& Childs, 2015; Pierce, Kostova, \& Dirks, 2001). This self-investment behavior can in turn lead to experiences of ownership over the online TV platform, even if no physical or legal ownership takes place, resulting in higher and longer use of the digital service (Kirk \& Swain, 2018). Furthermore, from a value creation perspective (Kumar \& Reinartz, 2016), the provision of a favorites functionality creates value for consumers by making it easier to navigate to preferred content. This in turn may lead them to use the online platform more frequently, thus giving value to the content provider as well (through an increase in subscription fees, advertising revenue and crucial consumer insights). Ideally, a virtuous circle ensues, with increased frequency of use resulting in the selection of more favorites, resulting in increased frequency of use, etcetera. To get there, however, consumers need to invest the time and effort required to draw up a favorites list. In line with the Fogg Behavior Model (Fogg, 2009), we posit they will only do this if they perceive the cost of 
working with the platform as low (i.e., the platform is easy to use), while perceiving the returns as high. Notably, in the context of digital entertainment, like online TV platforms, rewards for users are defined on multiple value dimensions. That is, not only in terms of functionality (finding the content one is looking for with relative ease), but also essentially in terms of consumers' hedonic experience (van der Heijden, 2004; Weniger \& Loebbecke, 2011). Hence, for developers of hedonic services, it is essential to not only focus on utilitarian benefits, but also to understand how hedonic experiences can result in benefits for the company, for example in terms of user loyalty (Chitturi, Raghunathan, \& Mahajan, 2008).

However, digital media use has been consistently found to vary by age and gender. Young men tend to be more technology-savvy on average and make more intensive use of a broader variety of available digital content platforms, including legal and illegal forms of downloading and streaming (Sinha \& Mandel, 2008; Weijters \& Goedertier, 2016; Weijters, Goedertier, \& Verstreken, 2014). It follows that for younger, male segments, the relative value (benefits vs. costs) of an online TV platform and its related functionalities will be differently construed as compared to women and older segments. A central hypothesis of the current study therefore is that the relations between frequency of use and number of favorites, as well as their relation with antecedent beliefs, will be fundamentally different for different demographic segments defined by age and gender.

In sum, the current study aims to contribute to the literature by focusing on how online TV content platforms can create value for consumers from a consumer centric perspective. More concretely, we will concentrate on the affordance of creating a list of favorites, which allows users to invest a part of their self in the service, rather than focusing on the content offered by the service. Furthermore, we investigate the interplay between this self-investment of users and the frequency of use of the platform. As a second contribution, we look at the demographical and attitudinal antecedents of use and self-investment from a technology 
acceptance perspective. Up to now, most studies on technology acceptance focus on a single point of adoption (e.g. Anton, Camarero, \& Rodriguez, 2013) or unspecified use behaviors in a technology (e.g. Lin, Featherman, \& Sarker, 2017). However, creating experiences in new technologies is a complex process and this often cannot be reduced to one general use behavior (Baxter et al., 2015). Therefore, we aim to investigate growth in two distinct yet interrelated behaviors (use and self-investment) in the light of technology acceptance antecedents.

Furthermore, our focus will be on a free platform. From a managerial perspective, this is especially relevant for two reasons. First, many incumbent broadcasters are forced online by intensifying competition from online video streaming platforms (e.g. Netflix) and could opt for a business model involving free use and advertisement based revenues. For these businesses it is key to understand not only adoption, but also continued use and the psychological mechanisms through which it can be triggered, such as self-investment. Second, research shows that paying for a digital service can increase value for users and can lead to more positive attitudes towards the service (Bagga, Bendle,\& Cotte, 2019; Verhagen, Feldberg, van den Hooff, Meents, \& Merikivi, 2012). However, this implies that new adopters are willing to pay for streaming services, while in practice this is not always the case. As discussed above, some broadcasters deliberately produce free content (with advertisement) and our research specifically aims to focus on the importance of non-financial types of selfinvestment (e.g. personal favorites lists) as antecedent of continued use in the context of free platforms, without the confounding of economic antecedents. We elaborate on this in the discussion section.

\section{Theoretical Background and Hypotheses}


Since the end of the twentieth century, digital technologies have changed the view of the entertainment sector. First of all, the introduction of Napster in the market has opened a door for file-sharing sites, where digital files could be transferred for free, without loss of quality. Due to this revolution, consumers no longer felt the need to pay for digital content (such as movies and TV series), since it has become very easy to copy these files without loss of data, and without monetary cost. Even the perceived risk of getting caught and the illegality of most of these sites is not considered as a large cost for most digital pirates, and is surpassed by the value of freely choosing what you watch whenever you want to watch it (De Corte \& Van Kenhove, 2017; Sinha \& Mandel, 2008). Secondly, the growth of Netflix as a video on demand (VOD) streaming service has made clear that consumers still find value in legal options with a higher apparent cost than illegal alternatives. Even though there is a higher monetary cost and the cost of giving your personal details to the service, consumers see higher value in an intermediary platform where information is bundled, where they can create a list of favorites for future use and where they get suggestions. Rather than focusing on creating value from content, or the core products, the focus of these legal intermediary platforms, for example Netflix, was initially on creating value from the context, or the 'extended product' (Bilton, 2017).

As a result of the emergence of new digital technologies and the pressure of filesharing sites and Netflix, many TV broadcasters decide to make the shift towards an online TV content platform as well, to retain their revenues. An important question, however, is how these online platforms can convince their users to keep using the platform. This continued use is necessary to extract value from the consumer and translate it in profit for the company (Kumar \& Reinartz, 2016), which can be achieved directly, for example by giving users who pay a subscription fee access to streams, or indirectly, for example by negotiating with advertisers for access to the user base (Andreassen et al., 2018). To investigate how continued 
use can be maintained by focusing on the extended product (rather than on content) as a company, this paper will construe trajectories of consumer use of an online TV platform over time as an indicator for continued use, and relate these trajectories to trajectories of selfinvestment, indicated by consumers' creation of a list of favorites. Thus, we can evaluate to what extent the possibility to create a list of favorites can add value for consumers. To do this as accurately as possible, we will compare the strength of the relation above between older and younger users and male and female consumers. Recent literature states that online platforms can create value for younger consumers, because they allow to catch up with the viewing habits of friends and to create a hedonically satisfying experience (Matrix, 2014) and especially the younger, male segments seem to find joy in exploring different media options (Weijters \& Goedertier, 2016). On the contrary, reasons why older consumers use online platforms are less documented. Given these findings, we expect that especially younger, male segments will interact more critically with an online TV platform and its related functionalities compared to women and older segments. In other words, they will switch between platforms more easily, in search for a platform that best meets their needs. From a practical point of view, this means that research into specific age and gender related interaction with online TV platforms should not only focus on content segmentation (Mares \& Sun, 2010), but that it can also be important for media companies to construe their online TV platforms in such a way that different segments have access to different functionalities.

To further explore the relationships between gender and age and trajectories of use and self-investment, we integrate in our model four attitudinal variables based on previous research from the piracy, self-service technologies and technology acceptance literature, namely perceived ease of use, perceived usefulness, social influence and perceived enjoyment. A simplified model is shown in Figure 1.

\section{Self-investment}


At the core of our model are consumers' individual trajectories over time for use of the streaming service as well as for self-investment in the service. One of the first notions on selfinvestment came from Pierce et al. (2001) in an organizational context, who stated that employees can increase attitudes towards their job through investment of their own ideas, unique knowledge, and personal style. Furthermore, they see creation as the most powerful form of self-investment, since this includes not only time and energy, but value and identity of the creator as well. Baxter et al. (2015) adapted this notion to a broader context and define self-investment as "the investment of personal resources, such as time, money, physical effort, and psychological energy in an object (p. 144)". Recently this form of investment is identified conceptually as an antecedent of continued use of digital technologies in relation to psychological ownership (Kirk \& Swain, 2018). Importantly, self-investment can be differentiated from other concepts such as company-driven personalization and customer engagement. While company-driven personalization is about presenting the right content to the right person at the right time (Tam \& Ho, 2005), self-investment requires a more active contribution from users to incorporate the platform in the extended self. Secondly, selfinvestment is also different from online customer engagement. In line with other forms of engagement, the latter can be defined as a broad, multi-dimensional, psychological state consisting of cognitive, emotional and behavioral dimensions (Marbach, Lages, \& Nunan, 2016). This is also reflected in the conceptualization of Hollebeek, Glynn, and Brodie (2014, p.154), which states that consumer brand engagement is "a consumer's positively valenced cognitive, emotional and behavioral brand-related activity during, or related to, specific consumer/brand interactions." Self-investment, on the other hand, is a more narrow concept and by definition behavioral in nature, but its link with customer engagement, either as antecedent or as facet, is still unclear. 
As mentioned earlier, one way to increase the self-investment of users is by only giving access to the online platform if users invest money. However, many online TV platforms operate through a free, advertisement-based service to compete with other video streaming services, and charging money is not desirable. Here, platform designers can encourage users to invest in other ways, for example by creating their own platform functionalities and by participating actively in the process to recall preferences (Baxter et al., 2015). Every time a user clicks the favorite button, this action is preceded by a process of consideration, which entails mental effort. Therefore the number of favorites can act as an indicator of self-investment. We believe that, when users actively create and maintain a list in which they indicate which TV programs are their favorites, users can actively create value themselves, since these actions allow them to quickly return to the programs they like. This leads to commitment to the online TV platform, which in turn leads to a higher customer lifetime value (Kumar \& Reinartz, 2016), sense of psychological ownership (Kirk \& Swain, 2018), willingness to pay for products (Fuchs, Prandelli, \& Schreier, 2010), purchase intention (Spears \& Yazdanparast, 2014) and word of mouth (Kirk, McSherry, \& Swain, 2015). Based on qualitative interviews and an online themed discussion group, Sinclair and Tinson (2017) also suggested that the construct of self-investment might act as a potentially strong driver of continued use. We propose that self-investment positively predicts continued use in line with the more general psychological mechanism where people tend to spend more time and effort in relations and endeavors in which they already invested (Rego, Arantes, \& Magalhes, 2018).

In the current study, we aim to investigate in a quantitative manner how selfinvestment, specifically users' creation of a list of favorites, is associated to the use of online TV channel platforms.

\section{The interplay between use and self-investment}


To fully understand the interplay between continued use and personal non-financial investment, our study is not limited to a unilateral investigation of the influence of selfinvestment on frequency of use, but we will research to what extent the effects are crosslagged. That is, we propose that use in a given period of time predicts the creation of favorites in a subsequent period as well. Evidence for this bidirectional relation can be found in the freemium business model literature, where insights suggest that using a free service, as an extended form of sampling, can increase both non-financial and financial consumer involvement in the service ( $\mathrm{Liu}, \mathrm{Au}, \&$ Choi, 2014). We specifically expect that with increased use, users have more occasions to invest time and effort in a service. The focus of the current study is specifically on non-financial investment, because this type of investment has been under-researched yet is increasingly important in the context of online services.

Since the interplay between use and self-investment is complex and the evolving nature of this interplay can be quite long, we cannot meaningfully investigate these two processes by merely focusing on the adoption of the service (Shih \& Venkatesh, 2004). In the current study, we focus on behavior after adoption of the digital streaming service, by following a longitudinal use-diffusion (UD) approach. This UD approach has some prominent advantages over more common adoption-diffusion (AD) approaches. In the first place, the UD approach enables us to investigate individually varying trajectories of two related processes over time, specifically frequency of use of a streaming service and the extent to which consumers invest in a personal list of favorites (i.e., self-investment) and makes it possible to differentiate between users with different use and investment trajectories, such as heavy and occasional users. This brings us to the first hypothesis of this study, where we study the relation between use and self-investment at different levels.

H1a: Higher use in a given period positively predicts increased self-investment in a subsequent period. 
H1b: Higher self-investment in a given period positively predicts increased use in a subsequent period.

Next, based on the literature, we formulate our second research goal of the current study, where we want to investigate how the attitudinal variables perceived ease of use, perceived usefulness, perceived enjoyment and social influence relate to (increase in) use and self-investment and, more importantly, we link both the behavioral trajectories, i.e. selfinvestment and use, and the attitudinal variables to individuals' gender and age. Where previous research mainly focused on the relation between attitudinal variables and the adoption or intention to use new forms of TV broadcasting from a technology acceptance perspective (Hino, 2015), we specifically use a UD approach, which allows us to relate trajectories of use, but also trajectories of self-investment to consumer attitudes towards the service. In the next paragraph, we delve deeper in the consumer attitudes that have been identified in the literature.

\section{Attitudinal antecedents of use and self-investment}

To form the attitudinal network around continued use and self-investment in our study, we primarily look at the technology acceptance literature. An extension of the Unified Theory of Acceptance and Use in Technology (UTAUT), the UTAUT2, incorporates different key antecedents of use intention and we use this framework as theoretical backbone of our own model (Venkatesh, Thong, \& Xu, 2012). First of all, in comparison with its predecessor (UTAUT; Venkatesh, Morris, Davis, \& Davis, 2003), the UTAUT2 is capable of explaining an increase of $12 \%$ of variance in behavioral use. Secondly, with the inclusion of hedonic motivation, this model is extremely suitable to explain technology acceptance in a consumer context, whereas UTAUT focuses on an employee technology acceptance and use setting (Venkatesh et al., 2012). In the following section, we discuss the four attitudinal antecedents 
that we have borrowed from UTAUT2 and their influence on both use and self-investment: perceived ease of use, perceived usefulness, perceived enjoyment and social norm.

\section{Perceived Usefulness and Perceived Ease of Use}

Perceived usefulness and perceived ease of use were identified as two of the first fundamental constructs important in predicting the amount of acceptance of a computer technology (Davis, Bagozzi, \& Warshaw, 1989). Later, these constructs were also incorporated and adapted to a consumer context in UTAUT2, respectively as performance expectancy and effort expectancy. In UTAUT2, perceived usefulness (or performance expectancy) refers to the expectation that the outcome of using the technology will provide benefits to consumers, whereas perceived ease of use (or effort expectancy) refers to the degree of ease associated with the consumers' use of the technology (Venkatesh et al., 2012). According to UTAUT2 if both constructs are evaluated positively, the behavioral intention to use it will be high.

Many studies already investigated the role of perceived usefulness and perceived ease of use in the use of the internet in general (Porter \& Donthu, 2006) and in the application of online TV (Hino, 2015; Jung, Perez-Mira, \& Wiley-Patton, 2009), and have found that perceived ease of use and perceived usefulness are indeed associated with the intention to use the technology. One of the main disadvantages of these studies, however, is that there is no quantification of the relation of both constructs with actual use after adoption. Furthermore, a study of Parthasarathy and Bhattacherjee (1998) compared continued adopters with discontinuers and found that people who stop using a service (discontinuers) gave lower perceived usefulness ratings of the service at point of adoption than continued users. These findings suggest that also within the group of continued adopters, overall usage frequency will be lower for users who perceive the service as less useful. In addition, it seems plausible that 
users with high perceived usefulness show an increase in use over time, but this remains untested until now.

Secondly, as research discussed above shows, perceived ease of use is also proven to be important for the adoption of a new technology. However, there is no reason to assume that perceived ease of use has a direct influence on the increase of usage over time. On the other hand, one can assume that a service will become easier to use when it is used more. Shih and Venkatesh (2004) state that prior experience leads to higher familiarity with a service, which in turn leads to a higher and more varied use. In line with these findings, a study of Gefen, Karahanna and Straub (2003) compares repeated customers of an online store with potential customers and clearly finds higher ratings of both familiarity and perceived ease of use in the first group. Furthermore, this study successfully establishes a link between familiarity and perceived ease of use, where familiarity has a positive influence on the latter. Since we are mainly interested in the unilateral effect of the antecedents on further trajectories of use, we will not further elaborate on this relation in the current study.

To address the gaps in the literature concerning the effects of attitudes on continued use over time, our research model allows to test the long term influence of both perceived usefulness and perceived ease of use. More concretely, especially for perceived usefulness positive effects on the increase of use over time are expected.

H2: Perceived usefulness positively predicts the slope of use over time of an online TV platform.

It is less clear how perceived usefulness and perceived ease of use of the platform will relate to self-investment. According to the multiple-goal pursuit model (Louro, Pieters, \& Zeelenberg, 2007), individuals tend to allocate more effort in response to perceived progress in goal realization. If the online TV platform is perceived to be useful, users assume that the 
service can help them realize their goals. As a consequence, it is expected that they will allocate more effort to the platform, including more self-investment behavior. Thus, we expect a positive relation between perceived usefulness and the growth in self-investment.

Next, when the perceived ease of use of an online TV platform is high, user's feelings of self-competence and determination may increase, resulting in exploration of the platform functions and features (Chau \& Lai, 2003). This may induce users to make optimal use of the platform and all of its options, including the favorites functionality, which leads to selfinvestment behaviors. This would imply a positive relation between perceived ease of use and (the slope of) self-investment. However, since perceived ease of use is based on the perceptions of efficiency of the platform to perform its primary function (McLean, 2018), functionalities that help structure the content may be used less when perceived ease of use is high. That is, users who experience no trouble whatsoever browsing the content on the platform may see limited use in creating a favorites list, implying a negative relation between perceived ease of use and (the growth in) this specific form of self-investment (i.e., number of favorites). Concretely, we propose an effect of perceived ease of use on self-investment. However, the direction of this effect is still unclear (hence, $\mathrm{H} 4$ will be formulated without explicitly positing a positive or negative direction of the relation). To sum up:

H3: Perceived usefulness positively predicts the slope of self-investment over time in an online TV platform.

H4: Perceived ease of use predicts the slope of self-investment over time in an online TV platform.

Extant research on technology acceptance has amply demonstrated the important role of social demographics in the relation between the TAM predictors and intention to use. Venkatesh and Morris (2000) state that men's usage heavily depends on the perceived 
usefulness of a technology. On the other hand, when the service is perceived as less useful, we expect that men abandon the service more quickly than women (i.e. their frequency of use will decrease). The main argumentation for this distinct emphasis on perceived usefulness between men and women is that men in general have more "masculine" traits such as assertiveness, which strongly correlate with more instrumental behaviors (Taylor \& Hall, 1982). While most research concerning perceived usefulness focuses on use intention, we believe that the same rationale can be used to propose gender effects in the relation between perceived usefulness and self-investment. That is, since men have a more instrumental focus, high perceived usefulness will be crucial to perform self-investment behaviors. We expect that this is less the case for women.

H5: The relation between perceived usefulness and use will be stronger for men than for women.

H6: The relation between perceived usefulness and self-investment will be stronger for men than for women.

Women, on the other hand, particularly attach importance to perceived ease of use when deciding whether or not to adopt and use a technology (Hino, 2015; Venkatesh \& Morris, 2000), leading us to expect a stronger relation between perceived ease of use and frequency of use for women. Weijters, Rangarajan, Falk and Schillewaert (2007) furthermore argue that men may use different information-processing strategies than women in using new technologies and functionalities. Where men tend to focus on making the platform more efficient, women may use the functionalities of the platform more if this does not make use of the platform more complicated. It is possible that gender differences on information processing have attenuated in the meantime, since technologies are all around us nowadays, as is also suggested in recent literature (Kim, Karatepe, Lee, \& Demiral, 2018). However, to test 
this possibility, we further investigate the moderating effect of gender on the relation between perceived ease of use and use and self-investment. Thus, we propose the following:

H7: The relation between perceived ease of use and self-investment will be stronger for women than for men.

\section{Perceived enjoyment}

One variable that has been added in UTAUT2 to the variables from the original technology acceptance model, is the hedonic motivation of consumers, or, as it is called in research on hedonic information systems, perceived enjoyment (van der Heijden, 2004). Initially, most research on technology acceptance and use of technologies was done in organizational contexts and even in these contexts, perceived ease of use and perceived usefulness cannot always explain most of the variance in use intentions (Legris, Ingham, \& Collerette, 2003). To translate findings to the field of consumer behavior, a broader understanding of the variables that can influence use of a technology is necessary. UTAUT2 underlines the role of perceived enjoyment as a crucial driver in a consumer context (Venkatesh et al., 2012). In line with this, research that clearly distinguishes utilitarian from hedonic information systems, finds that the predictive value of perceived enjoyment on the intention to use information systems is even higher than the predictive value of perceived usefulness (van der Heijden, 2004). A stream of research in the more recent field of selfservice technologies (SSTs) confirms this notion and states that in a service context (as is the current context of our study) consumer's perceived enjoyment while using the technology, is indeed an important antecedent of future use and continuance intention (Dabholkar \& Bagozzi, 2002; Seol, Lee, Yu, \& Zo, 2016; Weijters et al., 2007). Especially since TV is a part of the entertainment sector, it seems self-evident (and thus, no hypothesis to this effect will be formulated) that the enjoyment from using the online TV platform is a key predictor for fulfilling its primary function (i.e. watching TV shows). Furthermore, we believe that 
perceived enjoyment can also be linked to self-investment behaviors. Research on postconsumption feelings shows that customer loyalty is enhanced when hedonic needs are met (Chitturi et al., 2008). If consumers experience a high self-fulfilling value in the creation and maintenance of a list with their own preferred shows, reflecting in a perceived enjoyment towards the platform, they will continue performing this behavior in the future.

The relations between perceived enjoyment and frequency of use and self-investment that we propose, can be understood from the perspective of behavioral psychology as well. The Hook model (Eyal, 2014) states that hedonic rewards resulting from actions that users make can lead to an increase of the same actions in order to obtain the rewards again. Thus, enjoyment from actions in the online TV platform can lead to an increase of those behaviors.

H8: Perceived enjoyment positively predicts the slope of self-investment over time of an online TV platform.

\section{Social Influence}

Furthermore, one last factor that comes forward in many technology acceptance models, including UTAUT2, is social influence. Social influence is defined as "the degree to which an individual perceives that important others belief that he or she should use the new system" (Venkatesh et al., 2003; p. 451), and this factor influences intention and behavior especially when use of a new technology is mandatory (Hartwick \& Barki, 1994). However, in more recent literature, results show that not only in mandatory, but also in voluntary contexts, consumers' future behaviors can depend heavily on the perceptions of what others think they should do. In the entertainment sector, social influence was first identified as an important driver of illegal downloading behavior (Levin, Dato-on, \& Manolis, 2007). Apart from this, it is also recognized in more legal contexts, such as the use of mobile internet (Venkatesh et al., 2012) and the adoption of mobile TV platforms (Hino, 2015). Importantly, 
however, the effect of social influence on use intention seems to diminish when prior experience is taken into account. For illegal downloading behavior, for example, one could notice that the intention to download in the future is higher when the consumer already performed downloading behavior in the past, whereas social influence exerted by peers had no influence on this behavior anymore (Levin et al., 2007). Venkatesh and Morris (2000) argue that the effect of social influence on technology acceptance disappears after gaining experience, because experienced users attach more importance to their own views towards the service. Nonetheless, since our research focuses on demographic differences in use and selfinvestment, and since it is likely that different demographic groups may hold different social norms with regard to the service, we include social influence as a control variable.

To sum up, first, our theoretical model consists of some more established relations between the antecedents and continued use, measured as the number of days the online TV platform is used for watching TV series and movies within a specific time period. As an addition to these established relations, we specifically hypothesize relations of perceived usefulness and perceived enjoyment with growth in use of the platform. Second, instead of focusing solely on a general use of the platform, as is the case in many studies on technology acceptance, we differentiate between watching behavior (primary function of the platform) and self-investment behavior in relation with the antecedents. Concerning self-investment we specifically expect effects of perceived usefulness, perceived ease of use and perceived enjoyment.

\section{Age}

Because of increasing life expectancies and decreasing birth rates, the proportion of older consumers increases and this has important implications for marketing services, especially technology-based services. For instance, Yoon, Cole \& Lee (2009) recommend that marketers "adjust the context of the decision by presenting the product information in a more 
meaningful or user-friendly way" and point out that older consumers have built up a broader knowledge base, but may have issues dealing with novel contexts. Relatedly, aging decision makers have been found to spend less effort searching information (Mata \& Nunes 2010).

Research on the use of media technologies consistently finds rather strong age effects, with younger consumers typically being more open to new types of platforms (Papies, Eggers, \& Wlömert, 2011) and making more frequent use of a more varied set of available platforms, both legal and illegal ones (Dilmperi, King, \& Dennis, 2011; Gerlich, Lewer, \& Lucas, 2010; Weijters \& Goedertier, 2016; Weijters et al., 2014). By contrast, older consumers have been found to be more habituated to traditional media platforms (Weijters \& Goedertier, 2016) and are less interested in new technologies that mainly have a hedonic purpose (Chen \& Chan, 2011). If this is true, their perceived usefulness of a digital TV platform will be lower in comparison with younger consumers.

H9: Age negatively predicts perceived usefulness of an online TV platform.

Furthermore, even though older consumers acknowledge that new technologies bring many benefits, they still see computer-driven technologies as requiring much mental effort and have lower self-efficacy regarding computer use (Mitzner et al., 2010). In line with this, older adults prefer to have fewer options to choose from (Reed, Mikels, \& Simon, 2008) and, in some circumstances, less variety in their choices (Novak \& Mather, 2007). Given their more limited experience with a variety of digital platforms, they will probably experience such non-traditional platforms as less easy to use.

H10: Age negatively predicts perceived ease of use of an online TV platform.

Finally, given the generally lower innovativeness among older people (Steenkamp, Hofstede, \& Wedel, 1999), they are less open and eager to discover new digital technologies 
than younger users (Tellis, Yin, \& Bell, 2009). We expect that this will result in less perceived enjoyment towards the online TV platform.

H11: Age negatively predicts perceived enjoyment of an online TV platform.

Younger men in particular have been found to be more technology-savvy than other consumer segments (Gerlich et al., 2010; Molteni \& Ordanini, 2003) and to be more likely to use a variety of content platforms (Weijters \& Goedertier, 2016). Main reason for this is that younger men in general score higher on innovativeness and novelty seeking than other segments in general (Tellis et al., 2009) and especially so when it comes to new technologies (Chau \& Hui, 1998). From an analytical perspective, if young men are especially likely to have more positive attitudes towards the digital service, this implies that gender moderates the effect of age on the attitudinal variables, such that the decline in perceived ease of use, perceived usefulness, perceived enjoyment is stronger among men. We thus formally hypothesize:

H12: The negative relation between age and perceived usefulness of an online TV platform is stronger for men than for women.

H13: The negative relation between age and perceived ease of use of an online TV platform is stronger for men than for women.

H14: The negative relation between age and perceived enjoyment of an online TV platform is stronger for men than for women.

In addition to the hypothesized interaction effects of age and gender on the attitudinal antecedents of use and self-investment (i.e., perceived usefulness, perceived usefulness and perceived enjoyment), we will also model age and gender interaction effects on social influence, since the latter variable serves as a control variable and it is likely that social influence varies across demographic groups. 


\section{Model and Analytical Approach}

To research our hypotheses, we compose a latent growth model around the two behavioral variables frequency of use and self-investment, which we link to latent attitudinal constructs and age in a multigroup setting with gender as the grouping variable. Figure 2 shows our research model. Panel I of Figure 2 displays the latent growth model for use frequency (operationalized as days of use per time period) and self-investment (operationalized as number of favorites per time period) with cross-lagged effects and timespecific residual correlations between use and investment. This allows us to study the relation between these two behaviors at different levels of analysis: (a) at the between-individual level, we assess (the relation between) average levels of use and investment; (b) at the between-individual level, we also assess how an increase or decrease in use over time is associated with an increase or decrease in investment over time and vice versa; (c) across time, we study the cross-lagged effects from use to investment and vice versa; all the while controlling for (d) the time-specific level, where we estimate the correlation between timespecific use and investment. To clarify, components a and $\mathrm{b}$ refer to growth trajectories that vary across individuals, but are consistent over time within a given individual (an example would be a consistent increase in the number of favorites, where the increase is the same in each time period for a given individual, relative to an individually varying baseline level of favorites). By contrast, component c refers to the question of how the number of favorites created in a given period predicts the frequency of use in the subsequent period and vice versa (controlling for the individually varying trajectories). Finally, component $\mathrm{d}$ refers to the relation between number of favorites and frequency of use within the same period of time (e.g., within a given period higher use and the creation of more favorites may coincide).

Panel II contains attitudinal variables and age as antecedents of the latent growth factors as proposed in the hypotheses. Finally, in our model, gender affects all other variables 
in the model as well as their relations; that is, we hypothesize both main and interaction effects of gender.

We analyze our model through structural equation modeling with the default Maximum Likelihood estimator in Mplus 8.0 (Muthén \& Muthén, 1998-2017). Since our aim is to link a latent growth model to latent constructs in a multigroup setting, this is the most viable modeling approach.

To account for the fact that long-time users are likely to have built up a more extensive list of favorites and may have different usage frequencies, we include consumer relationship duration as a control variable. In addition, since usage is likely to be higher among users who have lots of spare time, we include the amount of free time as a control variable.

\section{Method}

As a study context, we selected a free video streaming platform in Belgium. The platform offers access to video content from all TV channels owned by a media company which has in its portfolio several TV channels, including the largest commercial (i.e., nongovernment owned) channel in the country under study. Users can live stream current broadcasting, and can additionally stream any content that has been broadcasted over the last several months. The app interface shows available content by means of graphical thumbnails with a show's title (by channel) and a heart-shaped icon that users can click to indicate favorites. The selected favorites are then kept in a favorites list that can be accessed as one of the tabs on the home screen (with the other two tabs being 'watching live' and 'browsing content'). The platform consists of a free, app-based video on demand streaming service.

The participants in our study were all users of the latter streaming service. At the time of data collection, access was free and the service generated revenue through advertising. To get access to the service, users had to subscribe and opt-in to the service's e-mailing list. The 
media company sent an e-mail invitation to a web survey developed by the media company to its 191.953 users (with the chance of winning an iPad Air 2 in a drawing) and obtained $N=$ 4136 completed surveys (response rate $=2.15 \%$ ), the data of which were merged with subsequent individual usage behavior data. In this final sample, 2267 participants are male (55\%), the age of the participants ranges from 10 to 98 years old $(M=43.37, S D=17.21)$, and average length of the user relationship was $M=260.60$ days $(S D=96.26)$. After comparing sample demographics with population information, we found a slight underrepresentation of men in our sample and that the group of younger users (15-24 years) is overrepresented at the expense of older age groups (Table 1).

The collected data consisted of three components. First of all, we were provided with behavioral data over four waves of 20 days each, which gave information about the following variables. The number of days participants were active on the platform during each wave serves as an indicator of frequency of use. Further, we included the number of favorites users selected per wave; to reduce skewness this variable was log-transformed after adding one (to avoid taking the natural logarithm of zero values) and used as an indicator of self-investment. Date of subscription was used to compute length of the consumer relationship, which serves as a control variable.

Secondly, the participants were asked to answer an online questionnaire in which we probed their attitudes towards the streaming service. This survey was taken just before the first wave of behavioral data, so we could use the attitudinal variables as antecedents of use and investment. The attitudinal items used a five point Likert format with response categories labeled strongly disagree, disagree, neither agree nor disagree, agree, strongly agree. Drawing from previous literature (Davis, Bagozzi, \& Warshaw, 1992; Venkatesh et. al, 2003), we used two items per attitudinal factor, translated to Dutch and adapted to the specific context of online TV platforms, in cooperation with the media company management and informally 
pretested among a convenience sample of users to optimize comprehensibility. Social influence (SI): People who influence my behavior think that I should use [the streaming service]; People who matter to me think I should use [the streaming service]. Perceived ease of use (PEU): [The streaming service] is user friendly; With [the streaming service] I can easily watch programs. Perceived usefulness (PU): Thanks to [the streaming service] I decide what I want to watch, when and where I want to; Thanks to [the streaming service] I don't have to worry about missing a program. Perceived enjoyment (PE): When I watch [the streaming service], I feel relaxed; Watching [the streaming service] is a moment of quality time for myself.

In a preliminary analysis, we tested the factor structure of the attitudinal variables using confirmatory factor analyses. First, since gender is used as the grouping variable in the main analysis, we verified that measurement invariance holds for the attitudinal factors. In support of measurement invariance, $\chi^{2}$ difference tests were non-significant with $\chi^{2}(4)=$ 4.059 for metric invariance and $\chi^{2}(4)=6.424$ for scalar invariance. The measurement model, in which each factor has two indicators loading on it fits the data well $\left(\chi^{2}(14)=43.948, p<\right.$ $.001 ; R M S E A=.020, C F I=.998, T L I=.97, S R M R=.007$; for this analysis, data for men and women were pooled, since measurement invariance was established). Table 2 presents evidence in support of the convergent and discriminant validity of these four factors. The composite reliability (CR) was used as a first indicator of the convergent validity of the scales (Fornell \& Larcker, 1981), and none of the factors' CR was below the recommended rule of thumb of 0.70 (Nunnaly, 1978), indicating that the constructs are reliable. Furthermore, we measured the average variance extracted (AVE) as a second indication of the convergent validity, which was sufficient (above 0.50) for each of the latent factors (Fornell \& Larcker, 1981). Also, for none of the factor pairs, shared variance exceeded the factors' AVE, indicating discriminant validity. As a last component of the data collection, we also collected 
demographic information (age and gender) and amount of free time ('How much free time do you have available (on a typical day) for hobbies and other activities you enjoy?' with response options less than 30 minutes, 30-60 minutes, 1-2 hours, 2-5 hours, 5-8 hours, over 8 hours). A correlation matrix is presented in Table 3.

\section{Results}

The overarching goal of this study was to examine the relationship between demographic variables, attitudes and two types of behavior (frequency of use and selfinvestment) of a video streaming service. As depicted in Figure 2, we constructed a Structural Equation Model with the following components: for use (days) and investment (favorites) we specified a two-process latent growth model, with freely correlating intercept and slope factors, cross-lagged effects from use to favorites and vice versa, and correlated residuals at each time point. The intercept and slope factors for use and self-investment were regressed on the attitudinal factors (perceived usefulness, perceived ease of use, perceived enjoyment and social influence), which each had two indicators. The attitudinal factors and latent growth model factors were regressed on age, as well as the control variables free time per day and consumer relationship duration. Age and free time were mean centered. We used gender as a grouping variable. This way, we can test for gender differences in the relations between the variables in our model (while controlling for main effects of gender). For identification, the factor means were set to zero in the male group (but freely estimated in the female group). The cross-lagged regression effect was constrained to be invariant across time (but could freely vary between men and women, like all structural parameters). The model fits the data well, with $\chi^{2}(220)=1015.103, p<.001 ; R M S E A=.042, C F I=.991, T L I=.986, S R M R=$ .015. Unless noted otherwise, we report unstandardized coefficients.

\section{Use and investment}


Though we did not specify hypotheses concerning the mean intercept and slope factors, for a full understanding of the results, the intercept estimates of the use and favorites growth factors are reported in Table 4 for men and women separately. The estimates are factor intercepts; that is, the estimates represent expected values conditional on average attitudes, age and free time, and a consumer relationship duration of zero. The results in Table 4 indicate that women show slightly and non-significantly higher average use of the streaming service. For both men and women, use shows a slight decline over time, but the average decline is non-significant for women, significant for men. The most important gender differences occur for the growth factors related to the number of favorites: women have more favorites on average (remember that the number of favorites has been log-transformed for analysis), and show a significantly steeper increase in the number of favorites over time.

The residual correlations between the intercept and slope factors for days ( $\left.i_{\text {days }}, \mathrm{s}_{\text {days }}\right)$ and favorites ( $\mathrm{i}_{\text {favs }}, \mathrm{S}_{\text {favs }}$ ) show the following results. The residual correlations between the intercept factor of days $\left(i_{\text {days }}\right)$ and the intercept factor of favorites $\left(i_{\text {favs }}\right)$ show that participants who tend to watch more ( $\left.\mathrm{i}_{\text {days }}\right)$, also select more favorites $(r=.322, p<.001$ for men, $r=.358$, $p<.001$ for women). Furthermore, for women, but not men, an increase over time in watching behavior ( $\mathrm{s}_{\text {days }}$ ) goes together with an increase in the number of favorites ( $\mathrm{s}_{\text {favs }}$ ) over time $(r=.053, p=.173$ for male $, r=.077, p=.010$ for female $)$. The frequency intercept $\left(\mathrm{i}_{\mathrm{days}}\right)$ and slope factors $\left(\mathrm{s}_{\text {days }}\right)$ are negatively correlated $(r=-.251, p<.001$ among men; $r=-.212, p$ $<.001$ among women), suggesting there is a ceiling effect that leads heavy users to no longer show an increase in use over time. The favorites intercept $\left(i_{\text {favs }}\right)$ and slope factors $\left(\mathrm{s}_{\text {favs }}\right)$ are not significantly correlated ( $r=.021, p=.461$ among men; $r=.030, p=.203$ among women). The intercept factor for days ( $\left.i_{\text {days }}\right)$ is also positively correlated with the slope factor for favorites ( $(\mathrm{s}$ favs $)(r=.121, p<.001$ among men; $r=.115, p<.001$ among women), suggesting that heavy users create increasingly more favorites over time. By contrast, the intercept factor 
for favorites $\left(i_{\text {favs }}\right)$ shows a slightly but significantly negative correlation with the slope factor ( $\left.\mathrm{s}_{\text {days }}\right)$ for days $(r=-.071, p=.045$ among men; $r=-.074, p=.030$ among women).

The cross-lagged effects show the following. First, in line with H1a, higher frequency of use of the technology leads to a higher self-investment in the next wave among men and women alike (for men: unstandardized estimate $B=.015, S E=.002, E s t . / S E=6.633, p<$ .001 ; for women: $B=.016, S E=.002, E s t . / S E=8.529, p<.001$; gender difference: $p=.867)$. Second, in partial support of $\mathrm{H} 1 \mathrm{~b}$, among women the number of favorites positively predicts frequency of use in a subsequent period $(B=.048, S E=.010, E s t . / S E=4.664, p<.001)$. This cross-lagged coefficient is not statistically significant among men, however $(B=.004, S E=$ $.011, E s t . / S E=.358, p=.721)$. This gender difference is significant $(p=.003){ }^{1}$

\section{Attitudes}

Table 5 shows the regression parameter estimates of the latent growth model factors and the attitudinal antecedents. When considering the relation between attitudes about the service and subsequent use of and investment in the service, results in Table 5 show the following. In partial support of $\mathrm{H} 2$, for men (but not for women, although the difference is not significant), perceived usefulness positively predicts increased use of the streaming service over time. Results are thus inconclusive regarding the moderating role of gender on this effect (H5). No evidence is found in support of $\mathrm{H} 3$ and H6. This suggests that perceived usefulness may have less predictive power than anticipated when it comes to self-investment, which after all is a secondary form of technology interaction (and less directly related to need fulfilment compared to actual use).

\footnotetext{
${ }^{1}$ We also estimated an unconditional multi-group growth model, without demographic and attitudinal antecedents. The results can be found in the web appendix.
} 
In partial support of $\mathrm{H} 7$, for men, but not for women, perceived ease of use has a negative effect on the intercept factor of favorites, suggesting that men who easily find their way in the offer of the streaming service, do not feel compelled to create favorites. Even though the gender difference for this relation is statistically significant, among women perceived ease of use is not significantly related to the favorites intercept factor. No other significant relations are evident for perceived ease of use.

In line with previous research, higher perceived enjoyment leads to a higher use of the platform ( $\left.i_{\text {days }}\right)$ in general. Furthermore, higher perceived enjoyment also leads to higher selfinvestment ( $i_{\text {favs }}$ ), for men and women alike. Remarkably, this is the only attitudinal driver that has a consistent positive effect on use and investment. For men (but not for women, although the difference is not significant), $\mathrm{PE}$ also positively relates to the favorites slope factor, partially in line with H8. That is, men who experience the streaming service as enjoyable, tend to show a stronger increase in the number of favorites they select. As proposed in the theoretical chapter, social influence has no significant influence on continued use, nor on self-investment.

Even though we formulated no hypotheses concerning gender main effects on the attitudinal factors, for completeness Table 6 reports factor intercept estimates for the attitudinal measures. For reasons of identification, the intercept terms were fixed to zero among men. Consequently, the intercept estimates in the female group are also estimates of the intercept difference between women vs. men (the latter being zero by specification). Women report higher PU and PE than men.

\section{Age effects}

Table 7 reports age effects (i.e., unstandardized regression weighs with age as the independent variable) by gender. Mostly in line with $\mathrm{H} 9, \mathrm{H} 10$, and H11, attitudes towards the 
streaming service seem to deteriorate with age. Among men all attitudinal variables show a significant decline with age, among women the effect is significant only for perceived ease of use and perceived enjoyment. The moderating effect of gender is statistically significant for perceived ease of use (H13) and perceived enjoyment (H14), but not for perceived usefulness (thus there is no support for H12). As for the latter, the effect is in the expected direction, but not statistically significant.

Even though we did not put forward specific hypotheses on these relations, we also accounted for direct effect of age on the intercept and slope factors of use and investment. For men and women alike, the favorites intercept factor is negatively related to age, indicating that older users invest less in the streaming service (by selecting fewer favorites). At the same, the frequency of use (days) slope factor is positively related to age, indicating that frequency of use increases with age, even though this relation is only significant among women.

Lastly, Table 8 reports estimates of the relations involving the control variables, namely the amount of free time users have and the length of the consumer relationship. In general, the length of the consumer relationship was positively related to both frequency of use and the amount of self-investment, which indirectly supports the presence of growth trajectories of both use and self-investment.

\section{Discussion}

In the current study, we explored online TV platforms as a new alternative for broadcasters to compete with rising online video on demand services such as Netflix. Because of the long-term interaction between a streaming service and the user, rather than focusing on the first point of adoption of the technology, we focused our research on the consumers' continued use through a use-diffusion model. Better understanding the interplay between use and self-investment over time constituted the first research objective of the current study. As a 
second research objective, we linked consumers' behavior (use and self-investment) to attitudinal variables (perceived ease of use, perceived usefulness, perceived enjoyment, and social influence) and two key consumer demographics, age and gender.

Concerning the first research goal, we found positive associations between consumers' average use of the digital service and self-investment in the service, which means that frequency of use tends to be high for consumers for whom self-investment is high. Furthermore, we found evidence that for women (but not for men) an intra-individual increase in the frequency of use over time goes together with an intra-individual increase in selfinvestment. The cross-lagged effect estimates showed that especially for women, selfinvestment in a given time period leads to a higher frequency of use in the subsequent time period and vice versa. For men, a higher frequency of use leads to a higher self-investment, but we did not find evidence for the effect of self-investment on frequency of use. A somewhat similar tendency shows up when assessing growth trajectories of self-investment, where on average, women have more favorites than men, and show a steeper increase in favorites over time. On the other hand, average levels of use are equal between men and women.

From a service development point of view, this suggests that women are more receptive for the 'extended product' or the functionalities around the core product, such as the possibility to create a list of favorites, whereas men mainly focus on the core product, or the content of an online TV content platform. This is an interesting finding in the question on how consumer value can be created. The customer lifetime value can increase when consumers help shape the service, but, based on our research, there are important gender differences in the amount of value that is created by this process. Even though we have not tested this directly, there is a possibility that especially women want to be able to invest a part of their identity in the service, and that service developers should offer different platform interactions 
to different segments, although further research is needed to uncover the specific psychological process behind this effect.

A possible explanation for the effect of self-investment on frequency of use can be found in the domain of psychological ownership. Sinclair and Tinson (2017) indicated that self-investment in an online service can increase a sense of psychological ownership towards the service. In other words, by investing personal information or preferences in the service, users can develop a feeling that the service or a piece of the service belongs to themselves (Pierce, Kostova, \& Dirks, 2003). Kirk and Swain (2018) further explored the role of psychological ownership in digital services and mentioned positive effects on word of mouth, willingness to pay and purchase intention. The link between psychological ownership and actual use is not yet tested and in future research, the role of psychological ownership as a mediating mechanism between self-investment and frequency of use should be further quantitatively validated.

As a second research goal, we linked the average frequency of use and investment and their trajectories over time to attitudinal variables and to consumers' age and gender. The attitudinal variables' impact on use and investment was rather limited, with one exception. As suggested by Bardhi and Eckhardt (2012) as a topic for future research in the domain of access-based consumption, we established a strong effect of the perceived enjoyment on using and investing in the online TV content platform. Perceived enjoyment is the only attitudinal driver that consistently leads to higher use and higher self-investment, both for men and women. In professional or organizational contexts, researchers often focus on functional attitudinal variables, such as perceived ease of use and perceived usefulness, to explain use of new technologies. However, it is important to remark that for leisure technologies, an intrinsically hedonic variable such as perceived enjoyment has strong effects, which is more in line with the predictors for using self-service technologies. 
It is notable that among men, we found a negative effect of perceived ease of use on the amount of favorites they made. This suggests that men are less likely to see the added value of making favorites, when it is easy to find what they are looking for already without using the favorites functionality. By contrast, there was a positive relation between the perceived usefulness and an increase in use for men, indicating a growing involvement the more they find what they want. This is in line with previous research (Venkatesh \& Morris, 2000), stating that men's usage is heavily dependent on the perceived usefulness of a technology. On the other hand, when the service is perceived as less useful, it is possible that men abandon the service more quickly than women, whereas women may keep using the service because of the self-investment that they made. Furthermore, previous research states that perceived ease of use plays an important role in adoption of a service (Hino, 2015). However, when assessing continued use after adoption, our research suggests that the effect of perceived ease of use on continued use is rather limited.

Finally, age also plays an important role. As expected, older people see streaming services as less easy to use and less hedonically rewarding, suggesting that they are perhaps less likely to change their previously formed habits and that they see new technologies as surplus, rather than a replacement for established alternatives. Also in line with expectations, the negative relation between age and the attitudinal variables was more outspoken among men than among women (although the difference was not significant for perceived usefulness).

\section{Theoretical implications}

Previous research on technology acceptance established strong relations between behavioral intention to use the technology on the one hand and utilitarian and hedonic antecedents on the other hand (Venkatesh et al., 2012). The current study contributes to extant theory by focusing on actual (objective) behaviors over time and by studying two interrelated 
behaviors instead of only one general approximation of use of digital services. First, the measurement of actual behaviors over time, in combination with questionnaires measuring antecedents, prevents biased findings due to common method variance, since a combination of behavioral and attitudinal data was used. This can result in more generalizable results and prevent an inflation of shared variance due to single source data (Podsakoff, MacKenzie, \& Podsakoff, 2012). Second, the main focus of our study is to investigate two different but interrelated behaviors in relation to technology acceptance. This is distinct from earlier studies, which mostly look at intention to use (adopt) or intention to continue using, without specifying the usage behavior. However, entertainment services become more and more interactive, with the consumer not only as end user but also as co-creator (Prahalad \& Ramaswamy, 2004). Nowadays, consumers can do more than only receiving value (e.g. by watching a TV show on a digital platform), they can also create value for themselves or for other people (e.g. by structuring their favorite TV shows and movies and/or share these with others). Specifying different behaviors and investigating how these behaviors relate to each other, helps understanding how consumers perceive value in digital services.

\section{Implications for practice}

Next, the study provides important insights for practice as well. First, concerning the design of services, it is interesting to see that relatively simple adaptations in the platform, such as the insertion of a favorites button, can enhance users' self-investment and use. This is in line with two affordance principles identified by Baxter et al. (2015), who state that platforms that embed processes of creation and preference recall enhance both attachment and self-investment behaviors of its users. In light of these principles, we can expect that our findings are not limited to online TV platforms, but can also be transferred to other contexts including music streaming and the gaming industry, where cloud gaming and subscription services may gain traction in the near future (Shea, Liu, Ngai, \& Cui, 2013). In music 
streaming platforms, for example, users' creation of playlists with their favorite music can be seen as a similar self-investment behavior. Nowadays, many music streaming platforms offer an abundance of (both customized and non-customized) playlists to their users. However, our research suggests that it is important to keep users motivated to create playlists themselves as well, in order to enhance feelings of self-investment. By offering too many playlists, users could feel that it is too easy to browse what they are looking for, discouraging platform exploration and self-investment behaviors.

Furthermore, it is even possible to generalize our ideas to social media, where selfinvestment is at the core of the user experience. However, since social media are mainly a tool to network with others, it could be that more social indicators of self-investment, such as the number of friends one has gathered, are important antecedents of continued use as well (Lin $\& \mathrm{Lu}, 2011)$

Furthermore, as in social media, allowing self-investment of consumers through the creation of a list of favorites could give value to the content provider in the form of crucial consumer insights. These insights could be translated directly in a customized landing page or customized suggestions for the user, resulting in a higher user loyalty (Coelho \& Henseler, 2012) and could even be sold to other companies for targeted advertising.

\section{Limitations and directions for future research}

As a context of study, we opted for a free online TV platform. This however places a restriction on the generalizability to subscription based streaming services (e.g. Netflix), where users have to pay a fee to get access to the platform. Bagga et al. (2019) argue that buying can evoke strong feelings of ownership towards the bought object and in turn increase the valuation of that object. Concerning digital services, this financial investment, or buying access to a service, could influence how users perceive value and alter the relations between 
non-financial self-investment, use and its attitudinal antecedents. This in turn could affect to what extent service developers should convince users to interact with the service. Since our study solely focused on free services, future research could investigate the moderating role of financial investment.

Second, we argued that self-investment behaviors can lead to experiences of ownership in an online TV platform, which in turn can lead to more positive attitudes and a higher and longer use of the service. However, we have to be cautious in interpreting this relation, as until now, this is only conceptually proposed and not yet empirically tested in the context of digital services. Future experimental research could take a closer look at the role of psychological ownership in linking self-investment behaviors and different outcomes.

Third, we repeatedly linked self-investment to consumers' identity and suggested that users can invest their own identity in the platform through the creation of a personal list of favorites. However, based on the definition of Baxter et al. (2015), self-investment can be seen more widely as the investment of personal resources. It is still unclear to what extent the creation of a list of favorites actually contributes to incorporating the platform or its content into the self. Further research could elaborate more on the link between self-investment and identity.

Fourth, in our model, the attitudinal variables were included at a single time point, acting as antecedents of the use and investment trajectories. It would be plausible to expect a more complex interplay between behavioral variables on the one hand and attitudinal variables on the other hand. For instance, increased investment could enhance perceived ease of use and/or perceived usefulness of the service (Gefen et al., 2003). In the initial dataset for this study, attitudinal measurements were available for each wave, but there were two reasons not to use these repeated measures in the analyses. First and foremost, preliminary analyses showed that the attitudinal variables were surprisingly stable, to the extent that some measures 
of the same construct did not show discriminant validity over time (i.e., shared variance exceeded .50 , which indicates that these measures actually constitute one time invariant factor rather than distinct time specific factors; discriminant validity is a key requirement for longitudinal as well as for mediating factors, however; Pieters, 2017), so that modeling time specific factors was problematic. Second, the substantial dropout rates over the course of the waves resulted in a less favorable ratio between the number of parameters and the number of observations, which in combination with increased model complexity resulted in estimation problems. In sum, adding repeated measures of the attitudinal variables would in the current study not add much value while adding a lot of complications. Future research, for instance using an even larger initial sample, could further explore the interplay between repeatedly measured attitudinal measures and behaviors over time.

Fifth, due to restrictions related to the anonymization of the data, it was not possible to perform additional tests comparing behavioral data of participants with these of other users of the video streaming platform. Since users of the streaming platform could freely choose to participate in the study, it is possible that a self-selection has occurred of users with a high usage intensity (or a positive usage development). This selection bias in turn could have affected the results.

Lastly, some measures we used in the current study were suboptimal in some regards, as a consequence of there being multiple parties involved in setting up the data collection. For instance, for "amount of free time", the scale is not accurately designed: there are some overlaps between the categories "30-60 minutes", "1-2 hours", "2-5 hours" and "5-8 hours". Future research might benefit from the use of more fine-tuned measures. 


\section{References}

Andreassen, T. W., Lervik-Olsen, L., Snyder, H., Van Riel, A. C. R., Sweeney, J. C., \& Van Vaerenbergh, Y. (2018). Business model innovation and value-creation: the triadic way. Journal of Service Management, 29(5), 883-906. doi:10.1108/JOSM-05-2018-0125

Antón, C., Camarero, C., \& Rodríguez, J. (2013). Usefulness, enjoyment, and self-image congruence: the adoption of e-book readers. Psychology \& Marketing, 30(4), 372-384. doi:10.1002/mar.20612

Bagga, C. K., Bendle, N., \& Cotte, J. (2019). Object valuation and non-ownership possession: how renting and borrowing impact willingness-to-pay. Journal of the Academy of Marketing Science, 47(1), 97-117. doi:10.1007/s11747-018-0596-3

Bardhi, F., \& Eckhardt, G. M. (2012). Access-Based Consumption: The Case of Car Sharing. Journal of Consumer Research, 39(4), 881-898. doi:10.1086/666376

Baxter, W. L., Aurisicchio, M., \& Childs, P. R. N. (2015). A psychological ownership approach to designing object attachment. Journal of Engineering Design, 26(4-6), 140-156. doi:10.1080/09544828.2015.1030371

Bilton, C. (2017). The disappearing product. Cheltenham: Edward Elgar Publishing.

Chau, P. Y. K., \& Hui, K. L. (1998). Identifying early adopters of new IT products: A case of Windows 95. Information \& Management, 33(5), 225-230. doi:10.1016/s03787206(98)00031-7

Chau, P. Y. K., \& Lai, V. S. K. (2003). An empirical investigation of the determinants of user acceptance of Internet banking. Journal of Organizational Computing and Electronic Commerce, 13(2), 123-145. doi:10.1207/s15327744joce1302_3

Chen, K., \& Chan, A. H. S. (2011). A review of technology acceptance by older adults. Gerontechnology, 10(1), 1-12. doi:10.4017/gt.2011.10.01.006.00 
Chitturi, R., Raghunathan, R., \& Mahajan, V. (2008). Delight by Design: The Role of Hedonic versus Utilitarian Benefits. Journal of Marketing, 72(3), 48-63. doi:10.1509/jmkg.72.3.48

Dabholkar, P. A., \& Bagozzi, R. P. (2002). An attitudinal model of technology-based selfservice: Moderating effects of consumer traits and situational factors. Journal of the Academy of Marketing Science, 30(3), 184-201. doi:10.1177/0092070302303001

Davis, F. D., Bagozzi, R. P., \& Warshaw, P. R. (1989). User acceptance of computer technology: a comparison of two theoretical models. Management Science, 35(8), 9821003. doi:10.1287/mnsc.35.8.982

Davis, F. D., Bagozzi, R. P., \& Warshaw, P. R. (1992). Extrinsic and intrinsic motivation to use computers in the workplace. Journal of Applied Social Psychology, 22(14), 1111-1132. doi:10.1111/j.1559-1816.1992.tb00945.x

De Corte, C. E., \& Van Kenhove, P. (2017). One Sail Fits All? A Psychographic Segmentation of Digital Pirates. Journal of Business Ethics, 143(3), 441-465. doi:10.1007/s10551$015-2789-8$

Dilmperi, A., King, T., \& Dennis, C. (2011). Pirates of the web: The curse of illegal downloading. Journal of Retailing and Consumer Services, 18(2), 132-140. doi:10.1016/j.jretconser.2010.12.004

Eyal, N. (2014). Hooked: How to build habit-forming products. Canada: Penguin Books Ltd.

Fetler, M. (1985). Sex-differences on the California statewide assessment of computer literacy. Sex Roles, 13(3-4), 181-191. doi:10.1007/bf00287909

Fogg, B. J. (2009). A behavior model for persuasive design. In Proceedings of the 4th international Conference on Persuasive Technology (p. 40). ACM. 
Fornell, C., \& Larker, D. F. (1981). Evaluating structural equation models with unobservable variables and measurement error. Journal of Marketing Research, 18, 39-50. doi: $10.2307 / 3151312$

Fuchs, C., Prandelli, E., \& Schreier, M. (2010). The Psychological Effects of Empowerment Strategies on Consumers' Product Demand. Journal of Marketing, 74(1), 65-79. doi:10.1509/jmkg.74.1.65

Gefen, D., Karahanna, E., \& Straub, D. W. (2003). Inexperience and experience with online stores: The importance of TAM and trust. Ieee Transactions on Engineering Management, 50(3), 307-321. doi:10.1109/tem.2003.817277

Gerlich, R. N., Lewer, J. J., \& Lucas, D. (2010). Illegal media file sharing: The impact of cultural and demographic factors. Journal of Internet Commerce, 9(2), 104-126. doi:10.1080/15332861.2010.503849

Hartwick, J., \& Barki, H. (1994). Explaining the role of user participation in information system use. Management Science, 40(4), 440-465. doi:10.1287/mnsc.40.4.440

Hino, H. (2015). TV Today, Mobile TV Tomorrow? Extrapolating Lessons from Israeli Consumers' Adoption of Innovative TV Viewing Technology. International Journal on Media Management, 17(2), 69-92. doi:10.1080/14241277.2015.1030748

Hollebeek, L. D., Glynn, M. S., \& Brodie, R. J. (2014). Consumer Brand Engagement in Social Media: Conceptualization, Scale Development and Validation. Journal of Interactive Marketing, 28(2), 149-165. doi:10.1016/j.intmar.2013.12.002

Iyer, D., \& Scherf, K. (2006). Making TV meaningful: consumers and IPTV applications. Google Scholar.

Jung, Y., Perez-Mira, B., \& Wiley-Patton, S. (2009). Consumer adoption of mobile TV: Examining psychological flow and media content. Computers in Human Behavior, 25(1), 123-129. doi:10.1016/j.chb.2008.07.011 
Kim, T. T., Karatepe, O. M., Lee, G., \& Demiral, H. (2018). Do Gender and Prior Experience Moderate the Factors Influencing Attitude toward Using Social Media for Festival Attendance? Sustainability, 10(10), 19. doi:10.3390/su10103509

Kirk, C. P., McSherry, B., \& Swain, S. D. (2015). Investing the self: The effect of nonconscious goals on investor psychological ownership and word-of-mouth intentions. Journal of Behavioral and Experimental Economics, 58, 186-194. doi:10.1016/j.socec.2015.04.013

Kirk, C. P., \& Swain, S. D. (2018). Consumer Psychological Ownership of Digital Technology. In Psychological Ownership and Consumer Behavior (pp. 69-90). Cham: Springer International Publishing. doi:10.1007/978-3-319-77158-8_5

Kumar, V., \& Reinartz, W. (2016). Creating Enduring Customer Value. Journal of Marketing, 80(6), 36-68. doi:10.1509/jm.15.0414

Legris, P., Ingham, J., \& Collerette, P. (2003). Why do people use information technology? A critical review of the technology acceptance model. Information \& Management, 40(3), 191-204. doi:10.1016/s0378-7206(01)00143-4

Levin, A. M., Dato-on, M. C., \& Manolis, C. (2007). Deterring illegal downloading: the effects of threat appeals, past behavior, subjective norms, and attributions of harm. Journal of Consumer Behaviour, 6(2-3), 111-122. doi:10.1002/cb.211

Lin, X. L., Featherman, M., \& Sarker, S. (2017). Understanding factors affecting users' social networking site continuance: A gender difference perspective. Information \& Management, 54(3), 383-395. doi:10.1016/j.im.2016.09.004

Liu, C. Z. C., Au, Y. A., \& Choi, H. S. (2014). Effects of Freemium Strategy in the Mobile App Market: An Empirical Study of Google Play. Journal of Management Information Systems, 31(3), 326-354. doi:10.1080/07421222.2014.995564 
Louro, M. J., Pieters, R., \& Zeelenberg, M. (2007). Dynamics of multiple-goal pursuit. Journal of Personality and Social Psychology, 93(2), 174-193. doi:10.1037/0022-3514.93.2.174

Marbach, J., Lages, C. R., \& Nunan, D. (2016). Who are you and what do you value? Investigating the role of personality traits and customer-perceived value in online customer engagement. Journal of Marketing Management, 32(5-6), 502-525. doi:10.1080/0267257x.2015.1128472

Mares, M. L., \& Sun, Y. (2010). The Multiple Meanings of Age for Television Content Preferences. Human Communication Research, 36(3), 29. doi:10.1111/j.14682958.2010.01380.x

Mata, R., \& Nunes, L. (2010). When less is enough: Cognitive aging, information search, and decision quality in consumer choice. Psychology and aging, 25(2), 289. doi:10.1037/a0017927

Matrix, S. (2014). The Netflix Effect: Teens, Binge Watching, and On-Demand Digital Media Trends. Jeunesse: Young People, Texts, Cultures. 6(1), 119-138. doi:10.1353/jeu.2014.0002

McLean, G. (2018). Examining the determinants and outcomes of mobile app engagement - A longitudinal perspective. Computers in Human Behavior, 84, 392-403. doi:10.1016/j.chb.2018.03.015

Mikos, L. (2016). Digital media platforms and the use of TV content: Binge watching and video-on-demand in Germany. Media and Communication, 4(3), 154-161. doi:10.17645/mac.v4i3.542

Mitzner, T. L., Boron, J. B., Fausset, C. B., Adams, A. E., Charness, N., Czaja, S. J., . . Sharit, J. (2010). Older adults talk technology: Technology usage and attitudes. Computers in Human Behavior, 26(6), 1710-1721. doi:10.1016/j.chb.2010.06.020 
Molteni, L., \& Ordanini, A. (2003). Consumption patterns, digital technology and music downloading. Long Range Planning, 36(4), 389-406. doi:10.1016/s00246301(03)00073-6

Morrow, P. C., Prell, E. R., \& McElroy, J. C. (1986). Attitudinal and behavioral-correlates of computer anxiety. Psychological Reports, 59(3), 1199-1204. doi:10.2466/pr0.1986.59.3.1199

Muthén, L.K., \& Muthén, B.O. (1998-2017). Mplus User's Guide. Eighth Edition. Los Angeles, CA: Muthén \& Muthén.

Novak, D. L., \& Mather, M. (2007). Aging and variety seeking. Psychology and Aging, 22(4), 728-737. doi:10.1037/0882-7974.22.4.728

Nunnally, J. C. (1978). Psychometric theory (2nd ed.). New York: McGraw-Hill.

Papies, D., Eggers, F., \& Wlömert, N. (2011). Music for free? How free ad-funded downloads affect consumer choice. Journal of the Academy of Marketing Science, 39(5), 777-794. doi:10.1007/s11747-010-0230-5

Parthasarathy, M., \& Bhattacherjee, A. (1998). Understanding post-adoption behavior in the context of online services. Information Systems Research, 9(4), 362-379. doi:10.1287/isre.9.4.362

Pierce, J. L., Kostova, T., \& Dirks, K. T. (2001). Toward a theory of psychological ownership in organizations. Academy of Management Review, 26(2), 298-310. doi:10.5465/amr.2001.4378028

Pierce, J. L., Kostova, T., \& Dirks, K. T. (2003). The state of psychological ownership: Integrating and extending a century of research. Review of General Psychology, 7(1), 84-107. doi:10.1037/1089-2680.7.1.84 
Pieters, R. (2017). Meaningful Mediation Analysis: Plausible Causal Inference and Informative Communication. Journal of Consumer Research, 44(3), 692-716. doi:10.1093/jcr/ucx081

Podsakoff, P. M., MacKenzie, S. B., \& Podsakoff, N. P. (2012). Sources of method bias in social science research and recommendations on how to control it. Annual review of psychology, 63, 539-569. doi:10.1146/annurev-psych-120710-100452

Porter, C. E., \& Donthu, N. (2006). Using the technology acceptance model to explain how attitudes determine Internet usage: The role of perceived access barriers and demographics. Journal of Business Research, 59(9), 999-1007. doi:10.1016/j.jbusres.2006.06.003

Prahalad, C. K., \& Ramaswamy, V. (2004). The future of competition: Co-creating unique value with customers: Harvard Business Press.

Reed, A. E., Mikels, J. A., \& Simon, K. I. (2008). Older adults prefer less choice than young adults. Psychology and Aging, 23(3), 671-675. doi:10.1037/a0012772

Rego, S., Arantes, J., \& Magalhes, P. (2018). Is there a Sunk Cost Effect in Committed Relationships? Current Psychology, 37(3), 508-519. doi:10.1007/s12144-016-9529-9

Seol, S., Lee, H., Yu, J., \& Zo, H. (2016). Continuance usage of corporate SNS pages: A communicative ecology perspective. Information \& Management, 53(6), 740-751. doi:10.1016/j.im.2016.02.010

Shih, C. F., \& Venkatesh, A. (2004). Beyond adoption: Development and application of a usediffusion model. Journal of Marketing, 68(1), 59-72. doi:10.1509/jmkg.68.1.59.24029

Sinclair, G., \& Tinson, J. (2017). Psychological ownership and music streaming consumption. Journal of Business Research, 71, 1-9. doi:10.1016/j.jbusres.2016.10.002

Sinha, R. K., \& Mandel, N. (2008). Preventing digital music piracy: The carrot or the stick? Journal of Marketing, 72(1), 1-15. doi:10.1509/jmkg.72.1.1 
Spears, N., \& Yazdanparast, A. (2014). Revealing obstacles to the consumer imagination. Journal of Consumer Psychology, 24(3), 363-372. doi:10.1016/j.jcps.2014.01.003

Steenkamp, J.-B. E., Hofstede, F. t., \& Wedel, M. (1999). A cross-national investigation into the individual and national cultural antecedents of consumer innovativeness. Journal of Marketing, 55-69. doi:10.2307/1251945

Tam, K. Y., \& Ho, S. Y. (2005). Web personalization as a persuasion strategy: An elaboration likelihood model perspective. Information Systems Research, 16(3), 271-291. doi:10.1287/isre. 1050.0058

Taylor, M. C., \& Hall, J. A. (1982). Psychological androgyny - theories, methods, and conclusions. Psychological Bulletin, 92(2), 347-366. doi:10.1037/0033-2909.92.2.347

Tryon, C. (2015). TV got better: Netflix's original programming strategies and the on-demand $\begin{array}{lllll}\text { television } \quad \text { Media } & \text { Industries (2). }\end{array}$ doi:10.3998/mij.15031809.0002.206.

Tellis, G. J., Yin, E., \& Bell, S. (2009). Global consumer innovativeness: Cross-country differences and demographic commonalities. Journal of International Marketing, 17(2), 1-22. doi:10.1509/jimk.17.2.1

van der Heijden, H. (2004). User acceptance of hedonic information systems. Mis Quarterly, 28(4), 695-704. doi:10.2307/25148660

Venkatesh, V., \& Morris, M. G. (2000). Why don't men ever stop to ask for directions? Gender, social influence, and their role in technology acceptance and usage behavior. Mis Quarterly, 24(1), 115-139. doi:10.2307/3250981

Venkatesh, V., Morris, M. G., Davis, G. B., \& Davis, F. D. (2003). User acceptance of information technology: Toward a unified view. Mis Quarterly, 27(3), 425-478. doi: $10.2307 / 30036540$ 
Venkatesh, V., Thong, J. Y. L., \& Xu, X. (2012). Consumer acceptance and use of information technology: extending the unified theory of acceptance and use of technology. Mis Quarterly, 36(1), 157-178. doi:10.2307/41410412

Verhagen, T., Feldberg, F., van den Hooff, B., Meents, S., \& Merikivi, J. (2012). Understanding users' motivations to engage in virtual worlds: A multipurpose model and empirical testing. Computers in Human Behavior, 28(2), 484-495. doi:10.1016/j.chb.2011.10.020

Weijters, B., \& Goedertier, F. (2016). Understanding today's music acquisition mix: a latent class analysis of consumers' combined use of music platforms. Marketing Letters, 27(3), 603-610. doi:10.1007/s11002-015-9349-y

Weijters, B., Goedertier, F., \& Verstreken, S. (2014). Online music consumption in today's technological context: putting the influence of ethics in perspective. Journal of Business Ethics, 124(4), 537-550. doi:10.1007/s10551-013-1892-y

Weijters, B., Rangarajan, D., Falk, T., \& Schillewaert, N. (2007). Determinants and outcomes of customers' use of self-service technology in a retail setting. Journal of Service Research, 10(1), 3-21. doi:10.1177/1094670507302990

Weniger, S., \& Loebbecke, C. (2011). Cognitive absorption: Literature review and suitability in the context of hedonic IS usage. Department of Business, Media and Technology Management, University of Cologne, Germany.

Yoon, C., Cole, C. A., \& Lee, M. P. (2009). Consumer decision making and aging: Current knowledge and future directions. Journal of Consumer Psychology, 19(1), 2-16. doi:10.1016/j.jcps.2008.12.002 


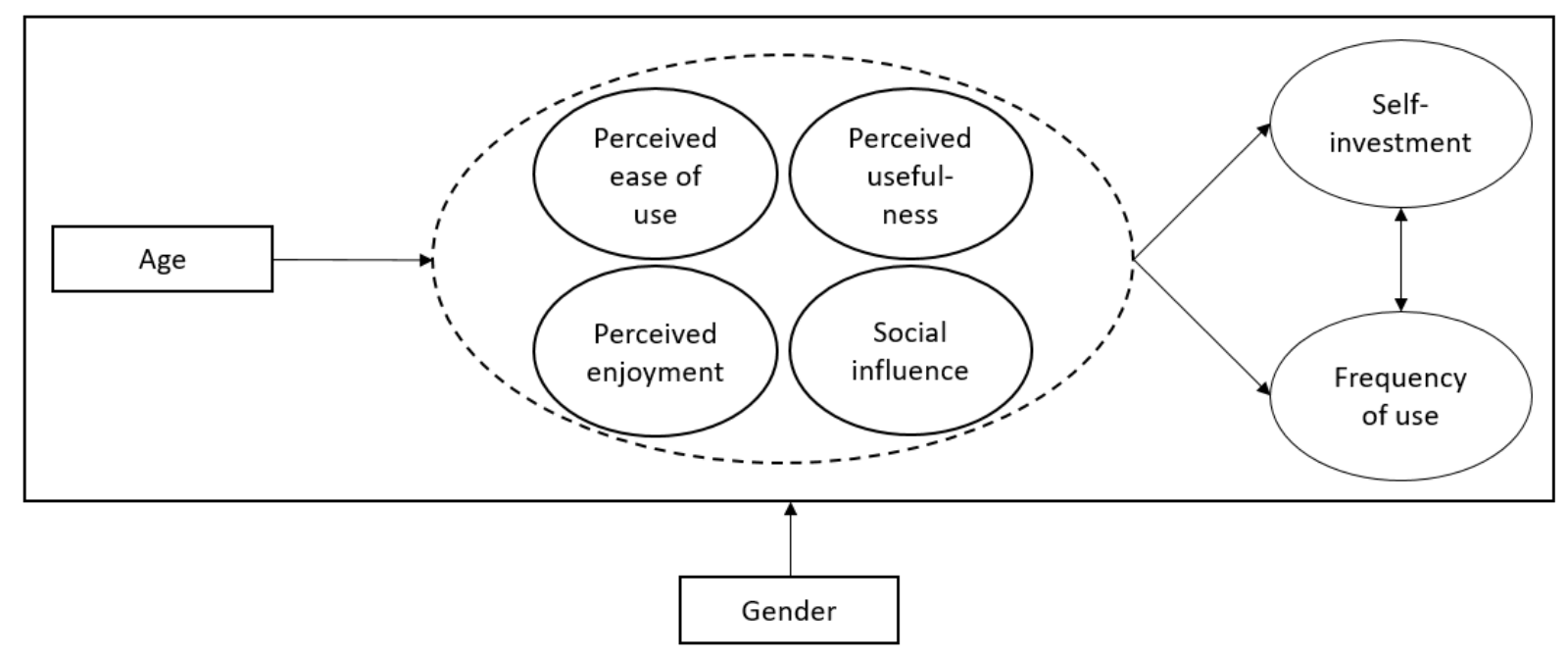

Figure 1 Simplified model. 


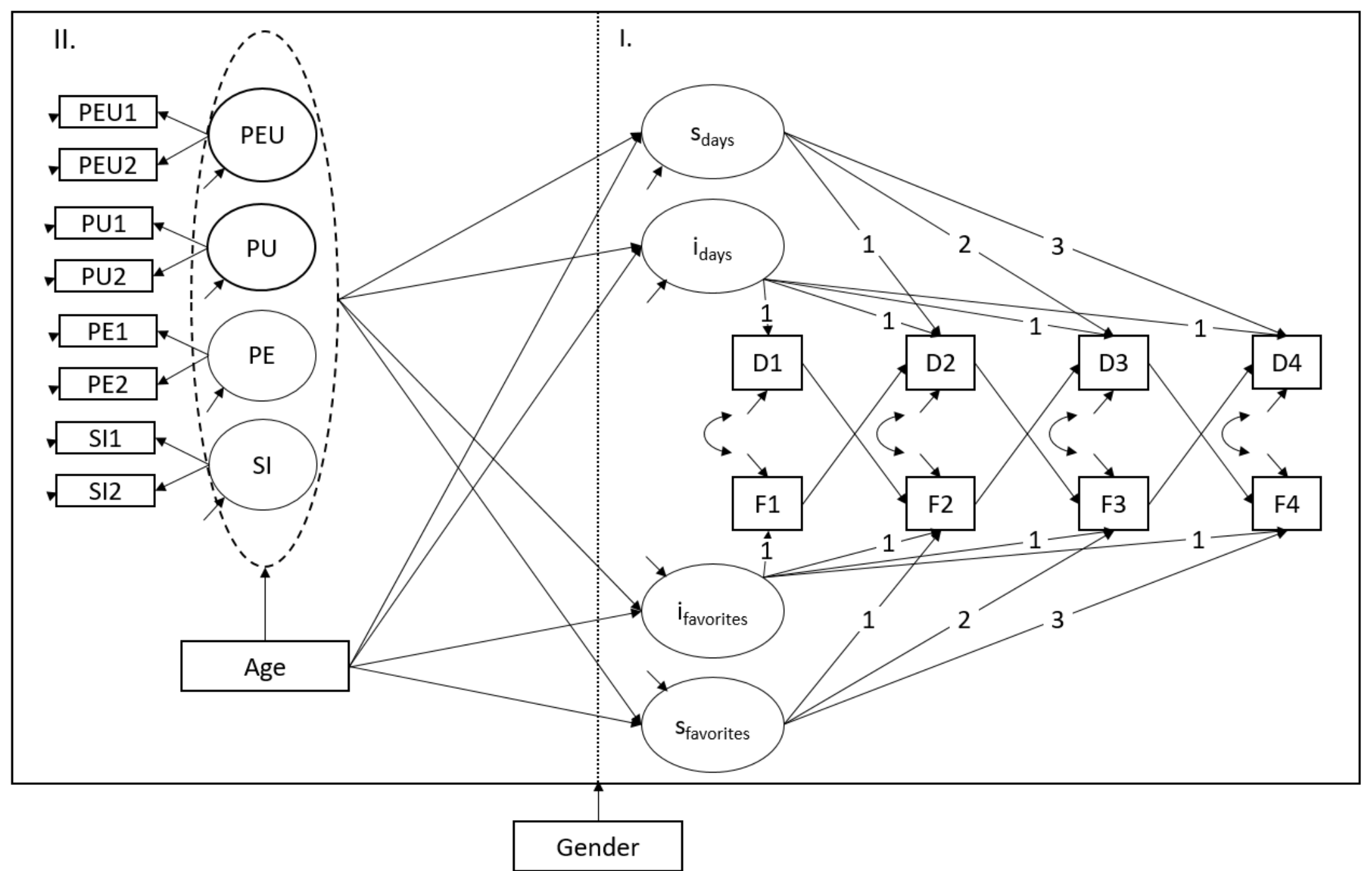

\section{Figure 2 Operational model.}

Note: $\mathrm{PEU}=$ perceived ease of use, $\mathrm{PU}=$ perceived usefulness, $\mathrm{PE}=$ perceived enjoyment, $\mathrm{SI}=$ social influence, $\mathrm{i}=$ latent intercept, $\mathrm{s}=$ latent slope, D1 through D4 = amount of days watched per wave, F1 through F4 = amount of favorites made per wave. Residual terms of the attitudinal factors (PEU, PU, PE, SI) freely correlate, as do the latent growth factors' residual terms. Gender is used as a grouping variable. 
Table 1: Comparison of distributions in the sample and in the population of the free online TV platform.

\begin{tabular}{llllll}
\hline & & Population & Sample & Chi Square & p-value \\
\hline Gender & Male & $62.5 \%$ & $54.8 \%$ & 104.58 & $<.001$ \\
& Female & $37.5 \%$ & $45.2 \%$ & & \\
\hline Age & & & & 898.21 & $<.001$ \\
(in years) & Younger than 15 & $0.4 \%$ & $0.9 \%$ & & \\
& $15-24$ & $9.9 \%$ & $21.7 \%$ & & \\
& $25-34$ & $21.7 \%$ & $13.8 \%$ & & \\
& $35-44$ & $21.4 \%$ & $16.2 \%$ & & \\
& $45-54$ & $21.5 \%$ & $16.8 \%$ & & \\
& $55-64$ & $15.9 \%$ & $18.7 \%$ & & \\
& Older than 65 & $8.4 \%$ & $12.0 \%$ & & \\
\hline
\end{tabular}


Table 2: Convergent and discriminant validity of the attitudinal measures

\begin{tabular}{llllll}
\hline Construct & C.R. & PEU & PU & PE & SI \\
\hline Perceived Ease of Use (PEU) & 0.83 & $\mathbf{0 . 7 1}$ & 0.44 & 0.34 & 0.06 \\
Perceived Usefulness (PU) & 0.77 & 0.661 & $\mathbf{0 . 6 3}$ & 0.40 & 0.10 \\
Perceived Enjoyment (PE) & 0.77 & 0.583 & 0.629 & $\mathbf{0 . 6 3}$ & 0.13 \\
Social Influence (SI) & 0.87 & 0.253 & 0.315 & 0.366 & $\mathbf{0 . 7 7}$ \\
\hline
\end{tabular}

Note: C.R. = composite reliability. Correlations below the diagonal; shared variance above the diagonal; AVE is depicted in bold on the diagonal. 
Table 3: Correlation matrix and descriptive statistics

\begin{tabular}{|c|c|c|c|c|c|c|c|c|c|c|c|c|c|c|c|c|}
\hline & 1. & 2. & 3. & 4. & 5. & 6. & 7. & 8. & 9. & 10. & 11. & 12. & 13. & 14. & 15. & 16. \\
\hline 2. Female & -0.152 & 1 & & & & & & & & & & & & & & \\
\hline 3. Free time & 0.274 & -0.086 & 1 & & & & & & & & & & & & & \\
\hline 4. Days active & 0.107 & -0.107 & 0.008 & 1 & & & & & & & & & & & & \\
\hline 5. PEU & -0.105 & 0.069 & -0.016 & -0.037 & 1 & & & & & & & & & & & \\
\hline 7. $\mathrm{PE}$ & -0.183 & 0.183 & -0.032 & -0.043 & 0.583 & 0.629 & 1 & & & & & & & & & \\
\hline 8. SI & -0.085 & 0.027 & -0.016 & -0.048 & 0.253 & 0.315 & 0.355 & 1 & & & & & & & & \\
\hline 9. D1 & -0.068 & 0.149 & 0.031 & 0.054 & 0.080 & 0.094 & 0.174 & 0.049 & 1 & & & & & & & \\
\hline 10. D2 & -0.062 & 0.161 & 0.020 & 0.050 & 0.078 & 0.093 & 0.174 & 0.056 & 0.840 & 1 & & & & & & \\
\hline 14. F2 & -0.157 & 0.213 & 0.017 & 0.069 & 0.083 & 0.099 & 0.189 & 0.046 & 0.389 & 0.383 & 0.349 & 0.358 & 0.994 & 1 & & \\
\hline 15. F3 & -0.158 & 0.215 & 0.017 & 0.068 & 0.083 & 0.099 & 0.190 & 0.048 & 0.388 & 0.384 & 0.356 & 0.361 & 0.989 & 0.994 & 1 & \\
\hline 16. F4 & -0.160 & 0.217 & 0.017 & 0.065 & 0.084 & 0.102 & 0.193 & 0.051 & 0.392 & 0.390 & 0.362 & 0.373 & 0.985 & 0.991 & 0.996 & 1 \\
\hline Mean & 43.37 & 0.45 & 3.35 & 260.60 & 4.22 & 4.11 & 3.93 & 2.59 & 2.19 & 2.36 & 2.06 & 2.17 & 5.41 & 5.73 & 5.81 & 6.01 \\
\hline$S D$ & 17.21 & 0.50 & 1.10 & 96.26 & 0.68 & 0.80 & 0.73 & 0.93 & 3.67 & 4.28 & 4.03 & 4.08 & 11.32 & 12.07 & 12.35 & 12.76 \\
\hline
\end{tabular}

Note: PEU = perceived ease of use, $\mathrm{PU}=$ perceived usefulness, $\mathrm{PE}=$ perceived enjoyment, $\mathrm{SI}=$ social influence, D1 through D4 = amount of days watched per wave, F1 through F4 = amount of favorites made per wave. 
Table 4: growth factor intercept estimates

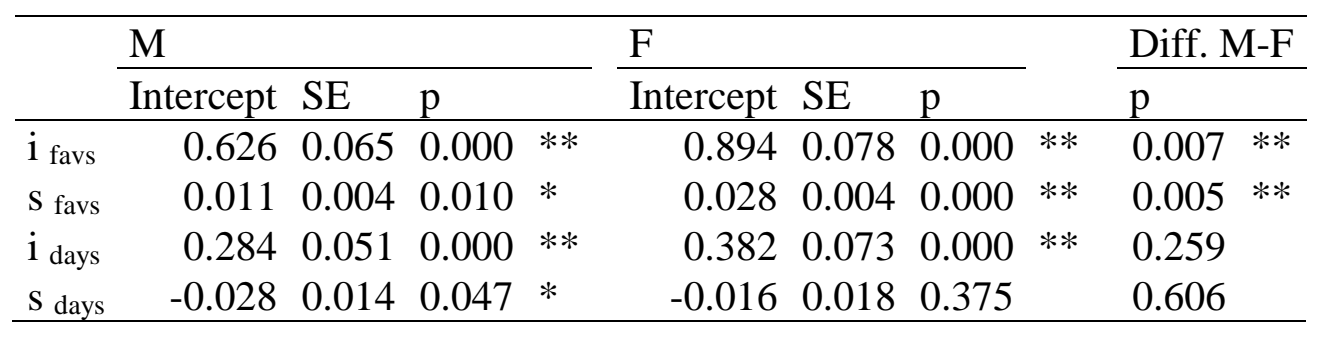

Note: see figure 2 for variable names. $\mathrm{M}=$ male, $\mathrm{F}=$ female. Diff $=$ difference between men vs. women. $\mathrm{SE}=$ standard error. $*=\mathrm{p}<.05, * *=\mathrm{p}<.01$. 
Table 5: Unstandardized regression weights for the growth and attitude factors, by gender

\begin{tabular}{|c|c|c|c|c|c|c|c|c|c|c|c|c|c|}
\hline \multirow[b]{2}{*}{ DV } & \multirow[b]{2}{*}{ IV } & \multicolumn{4}{|l|}{$\mathrm{M}$} & & \multicolumn{5}{|l|}{$\mathrm{F}$} & \multicolumn{2}{|l|}{ Diff. } \\
\hline & & Est. & SE & Est./SE & $\mathrm{p}$ & & Est. & SE & Est./SE & $\mathrm{p}$ & & $\mathrm{p}$ & \\
\hline \multirow[t]{4}{*}{$\mathrm{i}$ favs } & PEU & -.142 & .059 & -2.417 & .016 & $*$ & .084 & .079 & 1.072 & .284 & & .021 & * \\
\hline & PU & .038 & .064 & .592 & .554 & & -.063 & .082 & -.772 & .440 & & .330 & \\
\hline & PE & .330 & .060 & 5.537 & .000 & $* *$ & .297 & .087 & 3.420 & .001 & $* *$ & .752 & \\
\hline & SI & -.017 & .030 & -.561 & .575 & & -.069 & .040 & -1.734 & .083 & & .295 & \\
\hline \multirow[t]{4}{*}{$S$ favs } & PEU & -.003 & .004 & -.754 & .451 & & -.004 & .005 & -.809 & .418 & & .862 & \\
\hline & PU & .001 & .004 & .349 & .727 & & .003 & .005 & .577 & .564 & & .805 & \\
\hline & $\mathrm{PE}$ & .008 & .004 & 2.052 & .040 & $*$ & .003 & .005 & .567 & .571 & & .490 & \\
\hline & SI & .002 & .002 & 1.076 & .282 & & .004 & .002 & 1.785 & .074 & & .526 & \\
\hline \multirow[t]{4}{*}{$\mathrm{i}$ days } & PEU & -.011 & .046 & -.229 & .819 & & -.042 & .074 & -.566 & .571 & & .720 & \\
\hline & PU & -.026 & .050 & -.526 & .599 & & -.024 & .076 & -.308 & .758 & & .977 & \\
\hline & PE & .220 & .047 & 4.714 & .000 & $* *$ & .384 & .081 & 4.719 & .000 & $* *$ & .079 & \\
\hline & SI & .003 & .024 & .115 & .908 & & -.017 & .037 & -.455 & .649 & & .656 & \\
\hline \multirow[t]{4}{*}{$\mathbf{S}$ days } & PEU & -.023 & .013 & -1.821 & .069 & & -.001 & .018 & -.042 & .967 & & .315 & \\
\hline & PU & .033 & .014 & 2.353 & .019 & $*$ & -.002 & .019 & -.108 & .914 & & .143 & \\
\hline & $\mathrm{PE}$ & -.011 & .013 & -.882 & .378 & & .011 & .020 & .525 & .600 & & .360 & \\
\hline & SI & -.002 & .007 & -.272 & .785 & & -.010 & .009 & -1.081 & .280 & & .466 & \\
\hline
\end{tabular}

Note: see figure 2 for variable names. $\mathrm{M}=$ male, $\mathrm{F}=$ female. Diff $=$ difference between men vs. women. Est. $=$ estimate, $\mathrm{SE}=$ standard error. $*=\mathrm{p}<.05, * *=\mathrm{p}<.01$. 
Table 6: attitude intercept estimates for the female group

\begin{tabular}{lllrlll}
\hline & Est. & SE & Est./SE & $\mathrm{p}$ & \\
\hline PEU & .063 & .104 & .608 & .543 & \\
PU & .341 & .106 & 3.225 & .001 & $* *$ \\
PE & .526 & .110 & 4.767 & .000 & $* *$ \\
SI & .103 & .097 & 1.060 & .289 & \\
\hline
\end{tabular}

Note: see figure 2 for variable names. Est. $=$ estimate, $\mathrm{SE}=$ standard error. $*=\mathrm{p}<.05, * *=\mathrm{p}$ $<.01$. 
Table 7: age effects by gender (unstandardized regression weights)

\begin{tabular}{|c|c|c|c|c|c|c|c|c|c|c|c|c|}
\hline \multirow[b]{2}{*}{ DV } & \multicolumn{4}{|l|}{$\mathrm{M}$} & & \multicolumn{4}{|l|}{$\mathrm{F}$} & & \multicolumn{2}{|l|}{ Diff. } \\
\hline & Est. & $\mathrm{SE}$ & Est./SE & $\mathrm{p}$ & & Est. & SE & Est./SE & $\mathrm{p}$ & & $\mathrm{p}$ & \\
\hline PEU & -.053 & .009 & -6.044 & .000 & $* *$ & -.020 & .009 & -2.221 & .026 & * & .009 & $* *$ \\
\hline PU & -.043 & .010 & -4.376 & .000 & $* *$ & -.018 & .010 & -1.745 & .081 & & .089 & \\
\hline $\mathrm{PE}$ & -.092 & .010 & -9.633 & .000 & $* *$ & -.051 & .009 & -5.464 & .000 & $* *$ & .002 & $* *$ \\
\hline SI & -.051 & .011 & -4.674 & .000 & $* *$ & -.016 & .012 & -1.405 & .160 & & .027 & $*$ \\
\hline $\mathrm{i}_{\text {favs }}$ & -.066 & .013 & -4.997 & .000 & $* *$ & -.105 & .017 & -6.318 & .000 & $* *$ & .072 & \\
\hline $\mathrm{S}$ favs & .000 & .001 & .531 & .596 & & -.002 & .001 & -1.847 & .065 & & .089 & \\
\hline $\mathrm{i}_{\text {days }}$ & -.016 & .010 & -1.516 & .129 & & -.024 & .015 & -1.586 & .113 & & .642 & \\
\hline $\mathbf{S}$ days & .004 & .003 & 1.440 & .150 & & .012 & .004 & 3.043 & .002 & $* *$ & .114 & \\
\hline
\end{tabular}

Note: Age is the independent variable. See figure 2 for variable names. $M=$ male, $F=$ female. Diff $=$ difference between men vs. women. Est. $=$ estimate, $S E=$ standard error. ${ }^{*}=p<.05$, $* *=\mathrm{p}<.01$. 
Table 8: control variable standardized effect estimates

\begin{tabular}{|c|c|c|c|c|c|c|c|c|c|}
\hline \multirow[b]{2}{*}{ DV } & \multicolumn{2}{|c|}{$\mathrm{M}$} & \multicolumn{7}{|c|}{$\mathrm{F}$} \\
\hline & IV & Est. & SE & Est./SE & $\mathrm{p}$ & Est. & SE & Est./SE & $\mathrm{p}$ \\
\hline \multirow[t]{2}{*}{$\overline{\mathrm{PEU}}$} & Free time & -0.020 & 0.024 & -0.836 & 0.403 & 0.063 & 0.026 & 2.449 & 0.014 \\
\hline & Relation & -0.025 & 0.023 & -1.081 & 0.280 & 0.010 & 0.026 & 0.380 & 0.704 \\
\hline \multirow[t]{2}{*}{ PU } & Free time & 0.034 & 0.026 & 1.335 & 0.182 & 0.066 & 0.027 & 2.437 & 0.015 \\
\hline & Relation & 0.035 & 0.025 & 1.398 & 0.162 & -0.019 & 0.027 & -0.711 & 0.477 \\
\hline \multirow[t]{2}{*}{ PE } & Free time & 0.018 & 0.025 & 0.705 & 0.481 & 0.047 & 0.027 & 1.748 & 0.081 \\
\hline & Relation & 0.026 & 0.024 & 1.087 & 0.277 & -0.001 & 0.027 & -0.019 & 0.985 \\
\hline \multirow[t]{2}{*}{ SI } & Free time & 0.022 & 0.023 & 0.951 & 0.342 & -0.008 & 0.025 & -0.338 & 0.735 \\
\hline & Relation & -0.023 & 0.023 & -1.038 & 0.299 & -0.044 & 0.025 & -1.792 & 0.073 \\
\hline \multirow[t]{2}{*}{$i_{\text {favs }}$} & Free time & 0.082 & 0.021 & 3.870 & 0.000 & 0.042 & 0.023 & 1.825 & 0.068 \\
\hline & Relation & 0.263 & 0.010 & 27.181 & 0.000 & 0.125 & 0.023 & 5.495 & 0.000 \\
\hline \multirow[t]{2}{*}{$\mathrm{S}$ favs } & Free time & 0.003 & 0.026 & 0.124 & 0.902 & 0.005 & 0.027 & 0.182 & 0.855 \\
\hline & Relation & 0.061 & 0.009 & 6.792 & 0.000 & -0.066 & 0.026 & -2.508 & 0.012 \\
\hline \multirow[t]{2}{*}{$i_{\text {days }}$} & Free time & 0.055 & 0.024 & 2.355 & 0.018 & 0.063 & 0.025 & 2.569 & 0.010 \\
\hline & Relation & 0.184 & 0.010 & 18.857 & 0.000 & 0.092 & 0.024 & 3.812 & 0.000 \\
\hline \multirow[t]{2}{*}{$\mathrm{S}$ days } & Free time & -0.021 & 0.032 & -0.651 & 0.515 & -0.068 & 0.031 & -2.171 & 0.030 \\
\hline & Relation & -0.048 & 0.012 & -3.842 & 0.000 & -0.026 & 0.031 & -0.854 & 0.393 \\
\hline
\end{tabular}

Note: see figure 2 for variable names. Free time $=$ the amount of free time of a user per day, Relation $=$ length of the customer relationship, $\mathrm{M}=$ male, $\mathrm{F}=$ female. Est. = estimate, $\mathrm{SE}=$ standard error. 